\title{
Cut throat gashes: emergency tracheostomy as a relief
}

\section{Prem Nivas, Balaji Swaminathan, Ruta Shanmugam, Suji Govindarajan*, Thulasi Doss}

Department of ENT, Rajah Muthiah Medial College, Annamalai University, Chidambaram, Tamil Nadu, India

Received: 18 December 2019

Accepted: 04 January 2020

\section{*Correspondence:}

Dr. Suji Govindarajan,

E-mail: drsujigovindarajan@gmail.com

Copyright: ( ) the author(s), publisher and licensee Medip Academy. This is an open-access article distributed under the terms of the Creative Commons Attribution Non-Commercial License, which permits unrestricted non-commercial use, distribution, and reproduction in any medium, provided the original work is properly cited.

\begin{abstract}
Cut throat injury accounts for about 5 to 10 percent of all traumas. It is a life-threatening emergency condition. Cut throat injuries are challenging in terms of management as it necessitates close collaboration by otolaryngologists, anaesthetists, psychiatrists, speech therapists and general surgeons. Securing airway by emergency tracheostomy is always of prime concern to prevent impending complications such as haemorrhage, shock and asphyxia followed by closure of wound. This paper shares our experience with three patients who presented in emergency department with cut throat injuries of varying etiology who were treated diligently with a multidisciplinary approach. This paper is to emphasize the importance of securing airway by emergency tracheostomy under local anaesthesia.
\end{abstract}

Keywords: Cut throat injury, Tracheostomy, Neck zone, Cartilage injury

\section{INTRODUCTION}

Cut throat injuries are a life-threatening emergency accounting for 5 to $10 \%$ of all traumas. ${ }^{1}$ They are highly grievous injuries as most important structures are present in a relatively small area. Cut throat injury may be homicidal or suicidal. Suicidal cut throat injuries are rare in our population in contrary to western countries. The most common mode of cut throat injury is homicidal in developing countries like India. Laryngeal and tracheal injuries are most commonly associated with cut throat injuries. The most common site of tracheal transection is junction of cricoid with trachea as it is supported by weak connective tissue. ${ }^{2}$ The initial management is establishing a secure airway by emergency tracheostomy in view of anatomical distortion of larynx, and this may follow surgical repair of transected tissues. This paper emphasizes the importance of airway management in four patients who presented with deep cut throat injury in a time period of one year and was treated diligently with good final outcome.

\section{CASE REPORT}

\section{Case 1}

A 35 years old male patient was brought to casualty with alleged history of self-inflicted wound on the neck with antecedent history of depression due to unemployment. A $10 \mathrm{~cm}$ horizontal sharp wound extending across the midline just below the level of the hyoid bone exposing subcutaneous tissue, strap muscles and thyroid cartilage was seen. Zone II level of neck was involved. Air leak was present via the cut wound.

On failure of securing the airway with endotracheal intubation, emergency tracheostomy was done under local anaesthesia. On exploration, a horizontal contused lacerated wound of size $5 \mathrm{~cm}$ was seen below cricothyroid membrane and the defect was repaired using absorbable suture. The carotids, internal jugular vein and oesophagus was found to be normal. Corrugated drain kept and fixed to the skin. Wound closed in layers. On 
2nd post-operative day video direct laryngoscopy showed bilateral mobile vocal cords. Psychiatrist opinion was obtained concurrently and was discharged with tracheostomy tube on 8th post-operative day. Patient reviewed after a month, decannulation was done and wound closed. He was absolutely normal with good phonation and normal swallow after two months of his life-threatening injury.

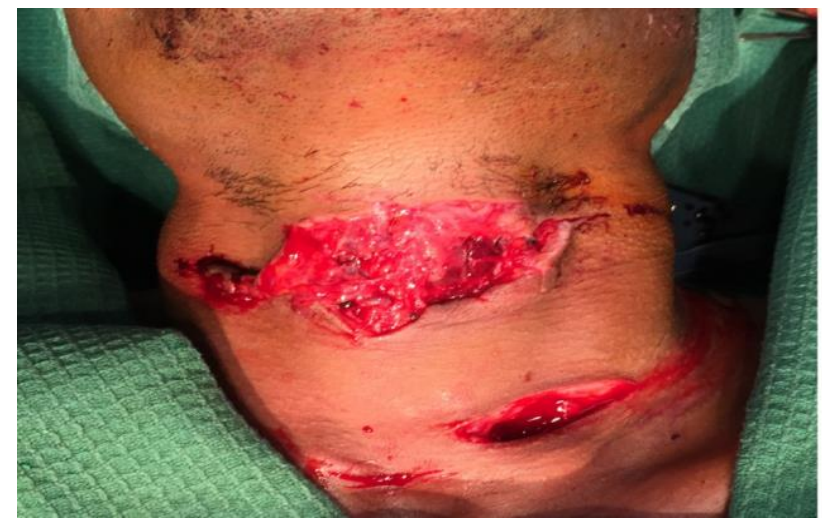

Figure 1: Suicidal cut throat injury exposing airway.

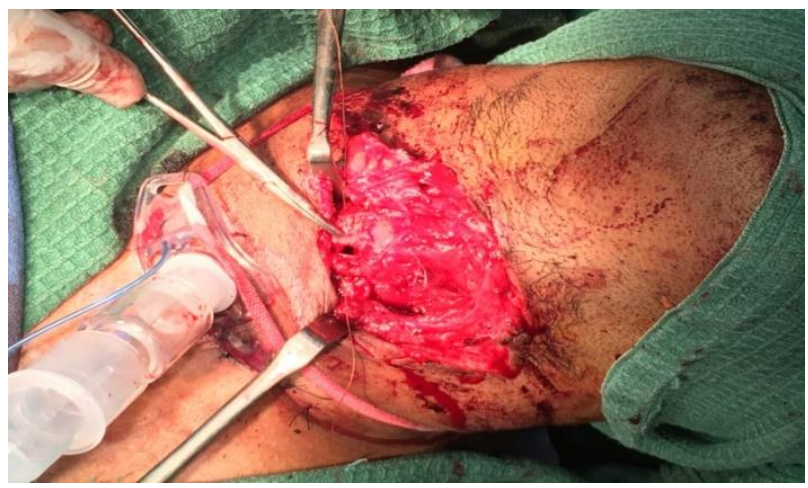

Figure 2: Emergency tracheostomy followed by wound repair.

\section{Case 2}

A 25 years old lady was brought to casualty with slaughtered neck by her husband due to a family dispute. On examination, a $4 \mathrm{~cm}$ laceration exposing laryngeal lumen seen in the midline of neck zone II. Air leak was present. Emergency tracheostomy was done under local anaesthesia.

On exploration of wound, thyroid cartilage was found to be fractured. Cartilage was repositioned and sutured using 3-0 prolene. Strap muscles were also sutured. No further air leak was noted. All major vessels found to be intact. Hemostasis secured. Wound closed in layers after placing corrugated drain. On 2 nd post-operative day endoscopy showed right side vocal cord palsy. Metal tracheostomy tube was changed on 8th post-operative day and patient was discharged. At 4th week post-operative review, video laryngoscopy showed normal vocal cord mobility with adequate glottic chink. Hence decannulation of tracheosotmy tube was done. Patient recovered completely after two months.

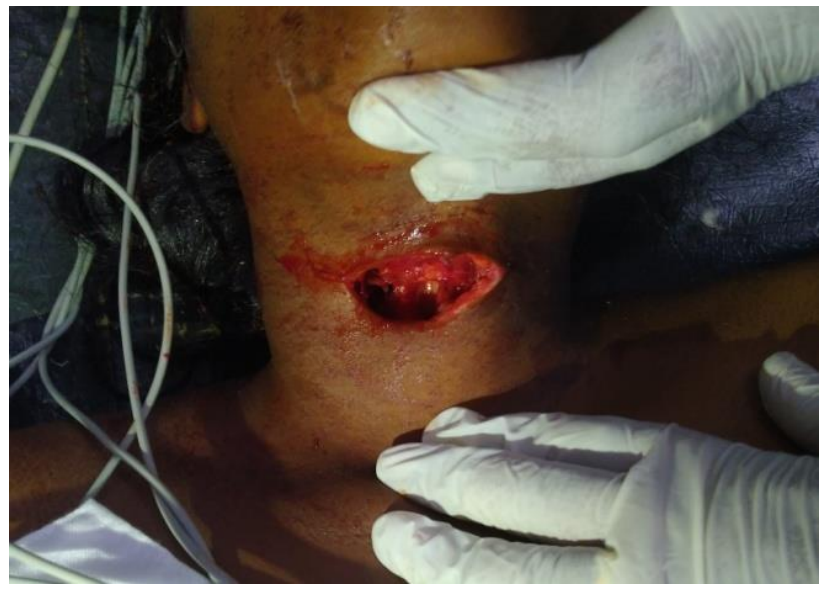

Figure 3: Homicidal cut throat injury incising the trachea.

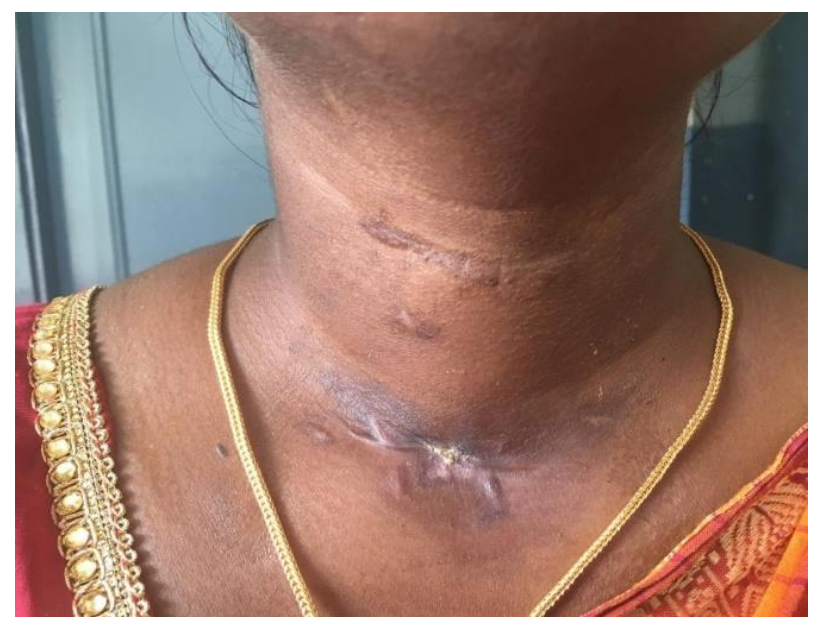

Figure 4: Post-operative follow up.

Case 3

A 65 years old female was brought to emergency department in semiconscious state with difficulty in breathing and bleeding profusely from neck injury following a chain snatch event. On examination, a laceration of size $15 \times 2 \mathrm{~cm}$, extending between anterior borders of sternocleidomastoid muscles was seen, exposing the laryngeal cartilage. Primary survey showed zone II level of injury. Patient had features of respiratory distress with saturation of $86 \%$. Emergency tracheostomy was performed under local anaesthesia followed by wound exploration under general anaesthesia. Tracheal laceration was seen between 1 st and 2 nd tracheal rings which was sutured using 3-0 prolene. Wound sutured in layers. Post-operatively patient was on assisted ventilation for 48 hours. On the 10th post-operative day video direct laryngoscope showed normal vocal cord mobility with normal subglottis. The patient recovered 
well and was discharged with Tracheostomy tube. Patient was on regular follow up. Decannulation was done after two months. Patient had excellent recovery on follow up.

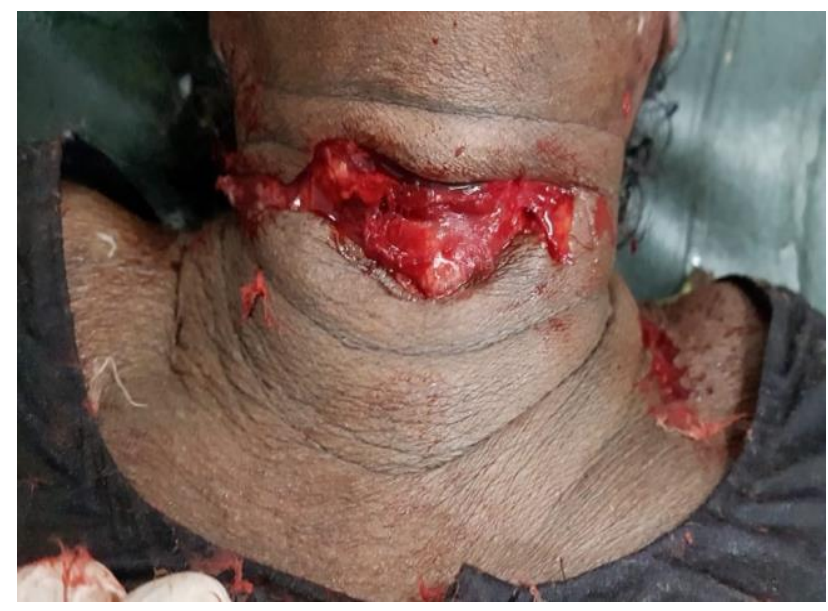

Figure 5: Homicidal cut throat with laceration involving laryngeal cartilage.
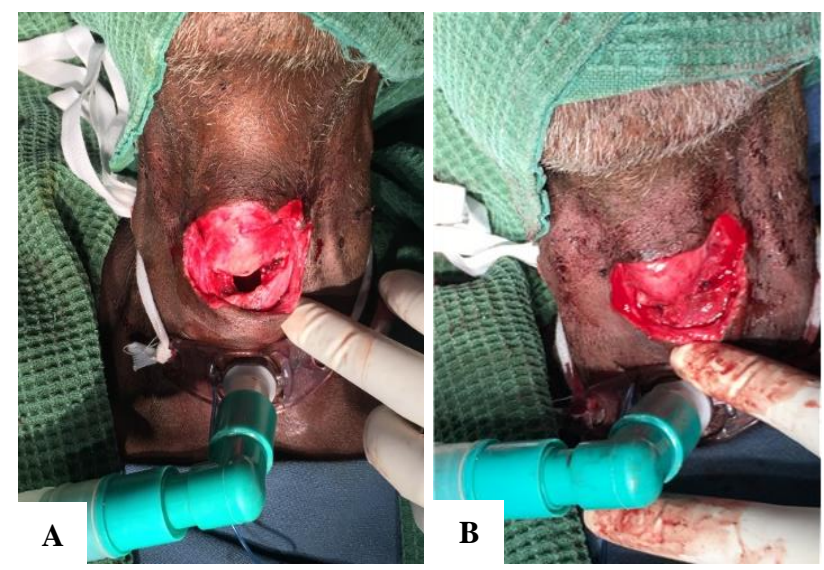

Figure 6: (A) Lacerated thyroid cartilage exposing the airway; (B) thyroid cartilage sutured.

\section{Case 4}

A 55 year old male presented in emergency room in conscious state and struggling to breathe with history of self-inflicted cut throat injury. Patient was under depression due to social stigma of pulmonary tuberculosis. On examination, a deep lacerated wound of size $5 \times 2 \mathrm{~cm}$ in anterior aspect of neck exposing the thyroid cartilage and airway was at risk. Emergency tracheostomy was performed under local anaesthesia. Following which patient was shifted to operating room. Under general anaesthesia, wound exploration was done. Thyroid cartilage was found to be lacerated which was sutured using 3' 0 prolene and wound sutured in layers using 3'0 ethilon. Post operatively patient recovered well and was under ventilator for two days. On 2nd postoperative day patient was shifted to room air. On 14th post-operative day videolaryngocope showed normal vocal cord mobility with good phonation and swallowing. Patient continued anti tuberculosis treatment and regular psychiatric counselling was given.

\section{DISCUSSION}

Cut throat injuries pose a great challenge as it most often involves vital structures. Patients may succumb to death before they reach medical echelon and so it is hardly reported in our medical literature. Neck injury induced by sharp objects involve larynx in $5-15 \%$ of patients and also chances of vascular and esophageal injury are much higher as likely as airway injury. ${ }^{3}$

Management of neck injuries depend on the anatomical level of injury. Roon and Christensen classified injuries of neck into three zones. Zone I bridge over cricoids superiorly to clavicle inferiorly. Zone II stretch across angle of mandible above and cricoid below. Zone III spanning the distance of skull base superiorly and mandibular angle inferiorly. Zone I and III are protected by bone and zone II grabs less osseous support and so the risk of injury is higher., ${ }^{3,4}$ Most of our patients encountered zone II injury.

The role of imaging in blunt or penetrating cut throat injury remains controversial, as there might be in delay in management and can lead to ruinous incidence. ${ }^{5}$ Thus we avoided subjecting our patient for any imaging procedure before stabilizing the patient.

Unshielded larynx or hypopharynx, haemorrhage, shock and asphyxia are most common cause of death in cut throat injury patients. These complications can be prevented by immediately securing the airway by emergency tracheostomy or intubation. ${ }^{6,7}$ Fibreoptic endoscopy is an useful aid for endotracheal intubation. ${ }^{8}$ Nevertheless, doing emergency tracheostomy is considered sensible in view of uncertainity about integrity of larynx. ${ }^{9}$

Tracheostomy is the most imperative measure from surgeon and also anaesthestic point of view. It provides clear surgical workspace and also prevents further complication of air embolism and aspiration pneumonitis. Beside this, it also handles the post-operative edema and also possibility of airway distress. ${ }^{10}$ Significant glottis or Supraglottic lacerations or significant disturbed cartilage fractures requires surgical repair.

In our patients, we had two homicidal and two suicidal case. Immediate management of airway if breached followed by wound exploration is the treatment of choice. All three of our patients presented with airway compromise and hence emergency tracheostomy was done following which wound exploration was done. Thyroid cartilage was fractured in two of our patients which was managed meticulously by suturing with 3'0 prolene. Fortunately, there was no vascular or esophageal injuries in our patients. All four patients had excellent wound healing and tracheostomy tube was decannulated 
at two months follow up with restoration of normal anatomical structure and no post-operative complications of stenosis or airway distress. Our patient recovered completely, as seen in review after three months.

\section{CONCLUSION}

Cut throat injuries are challenging in terms of management as it necessitates close collaboration by otolaryngologists, anaesthetists, psychiatrists, speech therapists and other specialities of surgeons. Securing airway is always of prime concern to prevent impending complications followed by closure of wound.

Funding: No funding sources Conflict of interest: None declared

Ethical approval: Not required

\section{REFERENCES}

1. Bhattacharjee N, Arefin SM, Mazumder SM, Khan MK. Cut Throat Injury: Retrospective Study of 26 Cases. Bangladesh Med Res Council Bull. 1997;23:87-90.

2. Cicala RS, Kudsk KA, Butts A, Nguyen H, Fabian TC. Initial evaluation and management of upper airway injuries in trauma patients. J Clin Anesth. 1991;3:91-8.

3. Rao BK, Singh VK, Ray S, Mehra M. Airway management in trauma. Indian. J Crit Care Med. 2004;8:98-105.
4. Roon AJ, Christensen N. Evaluation and treatment of penetrating cervical injuries. $J$ Trauma. 1979;19(6):391-7.

5. Miracle AC, Uzelac A. Imaging blunt and penetrating trauma to neck: Clinical relevance and management. Appl Radiol. 2016;45:14-9.

6. Ezeanoule BC. Management of the upper airway in severe cut throat injuries. Afr J Med Med Sci. 2001;30:233-5.

7. Eshiet A, Antiaue SG, Onoym IV,Edentekhe TA. Surgical airway problems and their management. The University of Calaban Teaching Hospital experience. Niger Postg Med J. 1979;4:15-8.

8. Prabhu M, Kulkarni M, Maddineni S. A novel method of airway management in a case of penetrating neck injury. Indian $\mathrm{J}$ Anaesthesia. 2016;60(7):509.

9. Varghese A. Penetrating Neck Injury: A Case Report and Review of Management. Indian J Surg. 2012;75(1):43-6.

10. Bhargava A, Gandhi B, Mahajan H. Anaesthetic management in cut throat injuries (A Report of Two Cases). Med J Armed Forces India. 1998;54(1):534.

Cite this article as: Nivas $\mathrm{P}$, Swaminathan B, Shanmugam R, Govindarajan S, Doss T. Cut throat gashes: emergency tracheostomy as a relief. Int J Otorhinolaryngol Head Neck Surg 2020;6:418-21. 